\title{
Unrestricted free access works and must continue
}

\section{Bioinformatics researchers shouldn't need coercion to act responsibly and collegially.}

Sir - The policy on release of unpublished

data from large genome centres has generated considerable discussion and some confusion, as your Editorial "Sacrifice for the greater good?" makes plain (Nature 421, 875; 2003). In our view, data sets from large, centralized, expensive genome data-collection projects should be freely available to the entire scientific community, immediately and with no restrictions or conditions.

Our position is that pre-publication release of large genome data sets is a special case, and not a principle that should be applied "throughout the world of biology", as was asserted in your editorial. Large genome sequencing has become an expensive, factory-style operation, in which economies of scale can only be realized by very large centres. Large data production centres, established and supported by the scientific community, represent a different model of science from traditional investigator-initiated projects. We argue that they need to operate under different rules.

The broader scientific community supports the highly centralized model represented by the US large-scale genome centres (funded via the National Institutes of Health and the Department of Energy) on the condition that everyone in this community gets equal access to the data. If this is the case, everyone wins: large data sets are generated at the lowest cost and greatest speed, and scientific work progresses on multiple fronts without delay. In contrast, if genome centres restrict their data and get preferential access to it, then some members of the community will no longer support monopolistic funding models (in which large centres sequence one genome after another without peer review of each project). Instead, they will demand the right to compete with these empires, especially for the most scientifically desirable genomes. Other scientists, especially bioinformaticians, will seek to relocate to the centres to gain the advantage of early data access. Data restrictions will therefore promote factionalization where we should be seeking efficiencies of scale, and centralization where we should be promoting diversity.

We agree with your editorial that the proposed new policy, recently released for comment by the US genome centres (see www.genome.gov/page.cfm?pageID= 10506537), is ambiguous. It states that genome sequence data "should be available for all to use without restriction". This statement, which notably uses the word "should" rather than "must", is qualified by a lengthy discussion of conditions, including a reference to the sequence producers' interest in "the first peerreviewed published analysis of the results of the sequencing project". This reflects the real concern of the genome centres that prepublication data access may put the scientists there at a competitive disadvantage. We understand these concerns, but we believe that the qualifying discussion cannot coexist with the principle of "without restriction". We propose that these qualifications are simply dropped to avoid confusion among data consumers, journals and journal reviewers. The Human Genome Project has been a spectacularly successful demonstration that the "Bermuda rules" of free access without restriction do work, for everyone.

As bioinformaticians, we have an important role in this process. We reaffirm our own commitment to respecting the

goals of the scientists at the genome centres, who should be consulted as part of any large-scale analysis of unpublished genome data, and included as collaborators where appropriate. It is a serious problem that these invaluable centres feel compelled to coerce such simple scientific courtesy from our community. We encourage our peers in bioinformatics to act responsibly, cooperatively and collegially, to help to assure open, unrestricted, immediate release from large community-driven data-collection projects.

Steven Salzberg ${ }^{\star}$, Ewan Birney†, Sean Eddy

* The Institute for Genomic Research, 9712 Medical Center Drive, Rockville, Maryland 20850, USA salzberg@tigr.org

$\dagger$ European Bioinformatics Institute, Wellcome Trust Genome Campus, Hinxton, Cambridge CB10 1SD, UK

$\ddagger$ Howard Hughes Medical Institute and Department of Genetics, Washington University School of Medicine, 4566 Scott Avenue, St Louis, Missouri 63110, USA

\section{Watching an IT icon slide into history}

Sir - In the famous photographs of James Watson and Francis Crick with their DNA model (reproduced in Nature $421,15 \& 417 ; 2003$ ) a small icon of information technology can be seen in Crick's right hand - a slide rule. (One wonders, incidentally, why this was shown in the photograph instead of the "measuring stick" which, together with a plumb line, they used "to obtain the relative positions of all atoms", as described by Watson in The Double Helix - anecdote has it that Crick told the

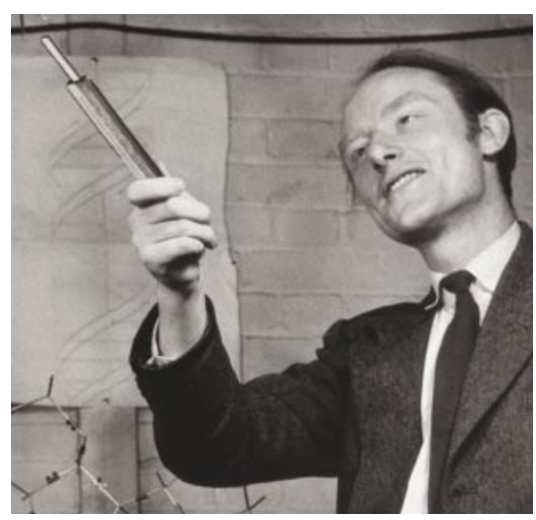

Ruled out: unlike Francis Crick, it seems that the slide rule is slowly being forgotten. insistent photographer that the slide rule was irrelevant.)

At Newcastle University we have been teaching biology students the use of computers for nearly three decades, beginning each year with a brief account of the staggering advances in computational power since the middle of the twentieth century. Each year, we show them an example of what Crick held. It seems fitting, on the fiftieth anniversary of the reconstruction of DNA, and at the advent of the rise of computational biology (C. Surridge Nature 420, 205; 2002), to report that this year, for the first time, none of our first-year students recognizes a slide rule.

\section{W. John Cram}

School of Biology, University of Newcastle upon Tyne, Newcastle upon Tyne NE1 7RU, UK

\section{Secrecy is increasing in step with competition}

Sir - Various authors and reports have recently claimed (for example, refs 1-3) that the increasing commercialization of academic science has led to an increase in secrecy. However, our comparison of two surveys of experimental biologists, mathematicians and physicists, conducted about 30 years apart, suggests a more 
complicated and interesting picture.

As feared, secrecy (measured as unwillingness to discuss ongoing research with those outside the research group) has increased.

In 1966 (ref. 4), 50\% of 1,042 respondents reported feeling safe in talking with all others about their current research, but by 1998, when we surveyed 202 scientists from the same three fields (details of methods and results available from J.W.), the equivalent number was $26 \%$. Experimental biologists have become particularly secretive, with only $14 \%$ willing to talk openly about their current research in 1998. Secrecy is strongly predicted by scientific competition (measured as concern over having one's research results anticipated). The effects of commercial activity, on the other hand, are quite mixed. Patenting has no effect; industry funding is associated with greater secrecy; but having industry collaborators is associated with less secrecy.

These university-industry collaborations can be viewed as part of a strategy to share findings and expertise with the wider scientific and technical community. For companies, timeliness and customization of information are often more important than exclusivity, so they are willing to tolerate, even encourage, their academic collaborators' participation in the shared conversation of a scientific field, thereby giving the company access to the whole community's expertise. In contrast to these collaborations, industry funding alone is often associated with a university laboratory acting as a subcontractor to a company's R\&D project, and may produce associated secretive behaviour.

Thus, there is reason to believe that secrecy has increased among academic scientists, but that the focus on commercialization as the cause may be misplaced. Although commercial activity may reduce formal activities such as publication or sharing of materials, it may have fewer negative effects on informal communication among researchers. As this informal communication is significant in transferring information to companies ${ }^{5}$ and is at least as important as publication for distributing information among scientists, this is encouraging news.

Although it is right to raise concerns about the negative effects of publication restrictions associated with industry funding, we should not conclude that university-industry linkages per se produce unhealthy levels of secretiveness among academic scientists. Instead, it may be better to focus on alleviating some of the negative consequences of scientific competition.
Recent increases in US government funding for science, if they are sustained, may help to lower the intensity of competition, as well as the dependence on industry funding, and thereby reduce secrecy. Furthermore, although we need to be wary of the strings attached to industry funding, university-industry collaborative research should be encouraged.

We thank Lowell Hargens for providing field-level data from ref. 4.

John P. Walsh ${ }^{\star} \dagger$, Wei Hong $\dagger$

${ }^{*}$ Research Center for Advanced Economic

Engineering, University of Tokyo, 4-6-1 Komaba,

Meguro-ku, Tokyo 153-8904, Japan

walsh@aee.u-tokyo.ac.jp.

$\dagger$ Department of Sociology, University of Illinois,

Chicago, Illinois 60607-7140 USA

1. Blumenthal, D. et al. J. Am. Med. Assoc. 277, 1224-1228 (1997).

2. Cook-Deegan, R. M. \& McCormack, S. J. Science 293, 217 (2001).

3. Campbell, E. G. et al. J. Am. Med. Assoc. 287, 473-480 (2002).

4. Hagstrom, W. O. Am. Sociol. Rev. 39, 1-18 (1974).

5. Cohen, W. M., Nelson, R. R. \& Walsh, J. P. Management Sci. 48, 1-23 (2002).

\section{Pre-genomics training hinders Indian biotech}

Sir - Ashok Parthasarathi in his

Commentary "India: a champion of new technologies" (ref. 1) rightly affirms India's bid to play a leading part in global technology developments. India's technological independence has come mainly in the physical sciences, such as space research, telecommunications, software, defence systems, energy and supercomputing.

Although Parthasarathi lists biotechnology as a key 'champion technology', a tremendous boost is needed for it to make a global impact.

India shares this predicament with other developing countries that have a vast research force but the training and infrastructure of pre-genomics days, and little experience of the research skills required for post-genomic biology. With the genome sequence data for several organisms, including humans, now available, the rules of knowledgebased commercial ventures have changed and an era of 'omics' - genomics, proteomics and so on - has emerged ${ }^{2}$, with functional genomics as the new 'mantra'.

In order to become a champion of biotechnology, India needs a paradigm shift in the organization of research and training, priming research institutions and universities to change gear and meet global challenges. Two aspects need urgent attention: establishing functionalgenomics centres for biotechnology and related basic science research, as is done in $\mathrm{China}^{3}$; and training researchers in state-of-the-art skills, along the lines of initiatives by the European Molecular Biology Laboratory.

All the stakeholders - in the fields of policy, administration, science and industry - have to address this problem and give a directional nudge to research initiatives.

Nature has covered some of these issues recently, for example the low impact factors of Indian biological-science journals ${ }^{4}$; the urgent need to explore the best scientific options for sustainable development by regional centres of the International Council of Science ${ }^{5}$; and the effect of post-genomics research on traditional methods of food production ${ }^{6}$. Informal articles on topics such as these serve as a compass for framing policies and making course corrections during implementation.

\section{R. M. Ranganath}

Department of Botany, Bangalore University, Jnanabharathi Campus,

Bangalore 560056, India

1. Parthasarathi, A. Nature 422, 17-18 (2003).

2. Palsson, B. Nature Biotechnol. 20, 649-650 (2002).

3. Cyranoski, D. Nature 410, 10-12 (2001).

4. Vohora, S. B. \& Vohora, D. Nature 412, 583 (2001).

5. Clarke, T. Nature 420, 733 (2002).

6. Knight, J. Nature 421, 568-570 (2003).

\section{Should tobacco ban rule out governments too?}

Sir - I was interested to read in your News story "Academics fume as university refuses to reject tobacco dollars" (Nature 422, 361; 2003) a scientist at the University of California, San Francisco, quoted as saying it is immoral to accept research funds from tobacco companies because "it is not appropriate to take money from an industry that kills 5 million people worldwide and constantly lies".

I guess that means that no research funds should be accepted from the US Department of Defense, nor from its corporate headquarters - the US government. Other national governments would presumably also be banned from supporting research under these new politically correct guidelines.

\section{Richard S. Jope}

Department of Psychiatry,

Sparks Center 1057, 17207 th Avenue South,

University of Alabama at Birmingham,

Birmingham, Alabama 35294-0017, USA

\section{correspondence}

Contributions to Correspondence may be submitted to corres@nature.com. They should be no longer than 500 words, and ideally shorter. Published contributions are edited. 